\title{
BMJ Open Endoscopic totally extraperitoneal (TEP) hernia repair for inguinal disruption (Sportsman's hernia): rationale and design of a prospective observational cohort study (TEP-ID-study)
}

\author{
C E H Voorbrood, ${ }^{1}$ E Goedhart, ${ }^{2}$ E J M M Verleisdonk, ${ }^{1}$ F Sanders, ${ }^{3}$ D Naafs, ${ }^{3}$ \\ J P J Burgmans ${ }^{1}$
}

To cite: Voorbrood CEH, Goedhart E,

Verleisdonk EJMM, et al. Endoscopic totally extraperitoneal (TEP) hernia repair for inguinal disruption (Sportsman's hernia): rationale and design of a prospective observational cohort study (TEP-ID-study). BMJ Open 2016;6:e010014. doi:10.1136/bmjopen-2015010014

- Prepublication history for this paper is available online. To view these files please visit the journal online (http://dx.doi.org/10.1136/ bmjopen-2015-010014)

Received 17 September 2015 Revised 30 October 2015 Accepted 2 December 2015

\section{CrossMark}

\begin{abstract}
${ }^{1}$ Department of Surgery, Diakonessenhuis, Utrecht/ Zeist, Zeist, The Netherlands ${ }^{2}$ KNVB/FIFA Medical Centre of Excellence (Sport Medical Centre of the Royal Netherlands Football Association/FIFA Medical Centre of Excellence), Zeist, The Netherlands ${ }^{3}$ Department of Radiology, Diakonessenhuis Utrecht/ Zeist, Zeist, The Netherlands
\end{abstract}

Correspondence to C E H Voorbrood; cvoorbro@diakhuis.nl

\section{ABSTRACT}

Introduction: Chronic inguinal pain is a frequently occurring problem in athletes. A diagnosis of inguinal disruption is performed by exclusion of other conditions causing groin pain. Up to now, conservative medical management is considered to be the primary treatment for this condition. Relevant large and prospective clinical studies regarding the treatment of inguinal disruption are limited; however, recent studies have shown the benefits of the totally extraperitoneal patch (TEP) technique.

This study provides a complete assessment of the inguinal area in athletes with chronic inguinal pain before and after treatment with the TEP hernia repair technique.

Methods and analysis: We describe the rationale and design of an observational cohort study for surgical treatment with the endoscopic TEP hernia repair technique in athletes with a painful groin (inguinal disruption).

The study is being conducted in a high-volume, single centre hospital with specialty in TEP hernia repair. Patients over 18 years, suffering from inguinal pain for at least 3 months during or after playing sports, and whom have not undergone previous inguinal surgery and have received no benefit from physiotherapy are eligible for inclusion. Patients with any another cause of inguinal pain, proven by physical examination, inguinal ultrasound, X-pelvis/hip or MRI are excluded.

Primary outcome is reduction in pain after 3 months. Secondary outcomes are pain reduction, physical functioning, and resumption of sport (in frequency and intensity).

Ethics and dissemination: An unrestricted research grant for general study purposes was assigned to the Hernia Centre. This study itself is not directly subject to the above mentioned research grant or any other financial sponsorship. We intend to publish the outcome of the study, regardless of the findings. All authors will give final approval of the manuscript version to be published.

\section{Strengths and limitations of this study}

- The complete assessment of groin pain with validated questionnaires and standardised physical examination by an experienced hernia surgeon, a specialised sports doctor and a dedicated radiologist.

- A strict selection of patients is carried out to assess the favourability of totally extraperitoneal patch (TEP) hernia repair technique for inguinal disruption.

- A limitation of this study is the absence of a control group with a different operation technique or even a 'sham' operation. However, in light of our hypothesis, we believe that not carrying out an operation (sham) would be morally unethical. We hypothesise that a weak inguinal floor may be a causative or contributory factor in the pathophysiology of an inguinal disruption, and that strengthening this weakened floor with a TEP repair may be of benefit to patients with this condition.

\section{BACKGROUND}

Inguinal disruption is a condition of chronic inguinal pain in athletes, with an incidence of $0.5-6.2 \% .^{1-3}$ Until recently, no consensus regarding nomenclature, diagnosis and treatment was available. ${ }^{1-4}$

Inguinal disruption is defined as groin pain when no other obvious pathology exists to explain the symptoms. ${ }^{1}$ Owing to its unclear aetiopathophysiology and the absence of a typical pattern of symptoms, no radiographic study can confirm the diagnosis of inguinal disruption and this will lead to deferred treatment. ${ }^{1}$ Furthermore, other pathology might be present simultaneously.

Appropriate treatment is important for fast resumption of sport activities of the athlete and is aimed toward its specific pathology. 
Management of inguinal disruption may start with conservative options (rehabilitation programmes, physiotherapy). ${ }^{1}$ Surgical repair may be necessary in patients with continuous inguinal pain. ${ }^{5-7}$

The totally extraperitoneal patch (TEP) hernia repair technique ensures a comprehensive view of the hernia floor. Moreover, the preperitoneal approach is associated with less chronic postoperative pain and a faster recovery in daily activities.

Endoscopic TEP hernia repair with implantation of a polypropylene mesh could, therefore, be an appealing technique for athletes with inguinal disruption. ${ }^{9} 10$

The aim of this manuscript is to describe the rationale and design of a prospective observational cohort study analysing outcomes of TEP hernia repair in athletes with inguinal disruption.

\section{METHODS AND DESIGN}

Study design

The study design is an observational, prospective cohort study. The study is designed to assess whether a systemic work-up of athletes with chronic groin pain can select patients who would benefit the most from surgical treatment using the TEP hernia repair technique. A highvolume hospital in the Netherlands (Diakonessenhuis Utrecht/Zeist), specialising in the TEP technique for inguinal hernia repair, will carry out the study in collaboration with the Royal Dutch Football Association (Koninklijke Nederlandse Voetbalbond/KNVB).

Resumption of sport (frequency and intensity), and pain parameters will be assessed preoperatively and at 1 , 2, 3, 4, 5, 6 and 12 weeks after surgery, measured by the Numeric Rating Scale (NRS) and the Copenhagen Hip and Groin Outcome Score (HAGOS). ${ }^{11} 12$

\section{Patient population}

Patients over 18 years, suffering from inguinal pain for at least 3 months during or after playing sports, and who have not undergone previous inguinal surgery and have received no benefit from physiotherapy (at least 12 treatments), and who have undergone a rest period from sports of at least 6 weeks are eligible for inclusion in this study. Patients with any another cause of inguinal pain (confirmed by physical examination, inguinal ultrasound, X-pelvis/hip or MRI) are excluded.

\section{Intake}

Patients are recruited during their first visit to the sportmedical outpatient clinic of the Royal Dutch Football Association (Koninklijke Nederlandse Voetbalbond, KNVB). Informed consent is obtained during this visit.

Anamnesis, functional testing and supplemental examination are performed at the sport-medical outpatient clinic of the KNVB.

Anamnesis focuses on the type of sport, duration of symptoms, presence of pain during sport, painprovoking factors, the duration, localisation, character and severity of the pain, history of previous surgery, the presence of an inguinal swelling, pain in other body areas and the presence of physical limitations. The use of pain medication and its effect is registered. Furthermore, previous history of consultations, imaging, and treatments (including the use of pain medication) and their effect is reported.

Physical examination includes inspection and palpation of the inguinal area and examination of sensory changes of the skin.

Functional testing includes range of motion of the hip joint, leg length discrepancy, anterior impingement test and FABERE test (impingement of the hip musculature), adductor squeeze test, Thomas test (flexibility of the iliopsoas muscle group), and Ely's test (tightness of rectus femoris). ${ }^{13-15}$

Supplemental examination performed is directed at finding abnormalities suggestive of other causes of inguinal pain: painful pubic tubercle on palpation (pubalgia), the test of Carnett (discerning visceral pain from parietal pain in anterior cutaneous nerve entrapment syndrome (ACNES), the test of Lasegue (spinal disc herniation), pain on the hip-adductor insertion (adductor tendinitis) or painful movement of the hip (bursitis iliopectinea, arthrosis).

In case of inguinal disruption, patients are recruited for the study and informed consent is obtained.

Inguinal disruption is defined as pain, either of a gradual or acute onset, which occurs predominantly in the groin area near the pubic tubercle and where no other obvious pathology, such as a hernia, exists to explain the symptoms. ${ }^{1}$

Athletes with chronic inguinal pain and diagnosed with inguinal disruption are referred to the Department of Surgery in the Diakonessenhuis Utrecht/Zeist. Physical examination is repeated and additional imaging is performed (ultrasonography, X pelvis/hip and MRI) for all patients. After exclusion of an inguinal hernia and other causes of groin pain, patients are planned for treatment using the TEP technique.

All data are collected using standard forms in Dutch: a self-designed Sportsmen form, the Numeric Rating Scale, and the Copenhagen Hip and Groin Outcome Score (HAGOS). ${ }^{11} 12$ The patient will fill in these standard forms assessing pain, the use of pain medication and restrictions in movements during activities preoperatively and at 1, 2, 3, 4, 5 and 6 weeks postoperatively. Resumption of sport (frequency and intensity) and parameters of pain will be assessed preoperatively, and at 1 , $2,3,4,5,6$ and 12 weeks after surgery.

\section{Interventions}

The perioperative care and surgical technique is standard for all patients undergoing this procedure and does not differ for patients participating in this study. The applied surgical method is the totally extraperitoneal patch technique for inguinal hernia repair using a mesh implantation technique and performed under general 
anaesthesia. A $10 \times 15 \mathrm{~cm}$, polypropylene monofilament mesh with small pores, weighing $80-85 \mathrm{~g} / \mathrm{m}^{2}$ (Prolene, Ethicon, Johnson \& Johnson company, Amersfoort, the Netherlands) is used in all patients. There is no consensus regarding the best mesh for endoscopic hernia repair. Recently, we performed a large RCT comparing lightweight Ultrapro and heavyweight Prolene mesh for TEP repair. In the early postoperative period up to 3 months, we did not find any difference in pain, discomfort, and quality of life between the two groups. ${ }^{16}$ The 2-year results have been analysed, and these showed significantly higher pain scores and higher hernia recurrence rates after use of Ultrapro mesh (unpublished results). Owing to the results of our previous findings, we decided to use Prolene in this study. The mesh is positioned in a tension-free manner in the preperitoneal space, as previously described. ${ }^{17}$ The mesh graft is not fixed, as fixation may induce pain due to nerve entrapment or haematoma. Intraoperative complications and operative time are registered in the Electronic Patient Chart (Dutch: EPD).

\section{Postoperative management}

Patients are discharged on the day of surgery and are advised to take analgesics (paracetamol and, if necessary, diclofenac), according to need and to avoid strenuous physical activity (lifting and sports) during the first postoperative week. There are no other (physical) restrictions.

\section{Follow-up}

The follow-up of patients is 3 months. The patient will fill in standard forms assessing pain scores, the use of pain medication and its effect, and restrictions in movements during activities preoperatively and 1, 2, 3, 4, 5 and 6 weeks postoperatively. Resumption of sport (frequency and intensity) and pain parameters will be assessed preoperatively, and 1, 2, 3, 4, 5, 6 and 12 weeks after surgery. Data are collected using standard forms in Dutch: Sportsmen form, the Numeric Rating Scale (NRS), and the Copenhagen Hip and Groin Outcome Score (HAGOS) ${ }^{11}{ }^{12}$ Intraoperative data are registered in the Electronic Patient Chart (Dutch: EPD).

After 6 weeks, the patients will visit the surgical outpatient clinic to assess pain parameters and possible postoperative complications. After 3 months, the patient will visit the sport-medical outpatient clinic of the Royal Dutch Football Association and will again fill in the same standard forms assessing pain and restrictions in movements during activities.

\section{Outcomes}

The primary outcome is the presence of pain 3 months after an endoscopic preperitoneal (TEP) hernia repair surgery and consists of a pain score measured by a Numeric Rating Scale (NRS).

Secondary outcomes are:
- Pain scores measured at rest and during activity preoperatively, and at 1, 2, 3, 4, 5 and 6 weeks postoperatively, using the NRS scale where $0=$ no pain and $10=$ extremely painful (Dutch version).

- Resumption of sport (in frequency and intensity) measured preoperatively, and at 1, 2, 3, 4, 5, 6 and 12 weeks postoperatively.

- Quality of Life is measured by the Copenhagen Hip and Groin Outcome Score (HAGOS) preoperatively, 1, 6 and 12 weeks postoperatively.

\section{Sample size calculation}

Limited data are available regarding pain scores after TEP hernia repair in athletes with inguinal pain. A study of Dojčinović et a $\tilde{l}$ shows that patients who underwent surgery for chronic groin pain that was unresponsive to conservative options had benefits from surgery. Pain scores measured by a Visual Analogue Scale were 6.49 preoperatively and 0.5412 weeks postoperatively. Based on a Cohen's effect size of 0.5 with a type 1 error, a significance level of $\alpha=0.05$ and a power of $80 \%$, the calculated sample size is 32 patients.

\section{Statistical methods}

Analyses will be performed using SPSS V.17.0 (SPSS, Chicago, Illinois, USA). Descriptive statistics were used for baseline data. Differences in preoperative and postoperative parameters will be analysed by means of a paired sample $t$ test (parametric data) or a Wilcoxon signed-ranked test (non-parametric data). Data will be compared to the reference values in the literature. Significance is set at a level of $\mathrm{p} \leq 0.05$ (two-sided).

\section{STATUS}

This study does not fall under the scope of the Medical Research Involving Human Subjects Act (WMO) in accordance with the regional Medical Ethics Committee (VCMO, Nieuwegein, the Netherlands), and the local Ethics Board of the Diakonessenhuis Utrecht/Zeist, the Netherlands. Estimated inclusion is 18 months beginning on the 1 January 2015. We expect to include 32 patients in total two patients per month during a period of 15 months with a follow-up of 3 months.

Contributors CEHV provided the conception and design of the article and drafted the manuscript. JPJB conceived the study, and has been involved in the design and the draft of the manuscript. EJMMV, EG, FS and DN have been involved in revising the manuscript critically for important intellectual content. All authors read and gave final approval of the version to be published.

Competing interests All authors hereby confirm that an unrestricted Research Grant has been assigned to Diakonessenhuis Utrecht/Zeist, or more specifically to the Hernia Centre Zeist, by Johnson \& Johnson. This physician-initiated study itself is not directly subject to the above mentioned Research Grant or any other financial sponsorship. Objectivity of the data is, therefore, guaranteed.

\section{Patient consent Obtained.}

Ethics approval Regional Medical Ethics Committee (VCM0, Nieuwegein, the Netherlands), and the local Ethics Board of the Diakonessenhuis Utrecht/Zeist, the Netherlands. 
Provenance and peer review Not commissioned; externally peer reviewed.

Data sharing statement Data are available for all authors who did meet the criteria for authorship. Data are stored in SPSS.

Open Access This is an Open Access article distributed in accordance with the Creative Commons Attribution Non Commercial (CC BY-NC 4.0) license, which permits others to distribute, remix, adapt, build upon this work noncommercially, and license their derivative works on different terms, provided the original work is properly cited and the use is non-commercial. See: http:// creativecommons.org/licenses/by-nc/4.0/

\section{REFERENCES}

1. Sheen AJ, Stephenson BM, Lloyd DM, et al. "Treatment of the sportsman"s groin': British Hernia Society's 2014 position statement based on the Manchester Consensus Conference. Br J Sports Med 2014;48:1079-87.

2. Kingston JA, Jegatheeswaran S, Macutkiewicz C, et al. A European survey on the aetiology, investigation and management of the "Sportsman's Groin." Hernia 2014;18:803-10.

3. Campanelli G. Pubic inguinal pain syndrome: the so-called sports hernia. Hernia 2010;14:1-4.

4. Harmon KG. Evaluation of groin pain in athletes. Curr Sports Med Rep 2007;6:354-61. http://www.ncbi.nlm.nih.gov/pubmed/18001606 (accessed 6 Oct 2014).

5. Dojčinović $B$, Sebečić $B$, Starešinić $M$, et al. Surgical treatment of chronic groin pain in athletes. Int Orthop 2012;36:2361-5.

6. Paajanen $\mathrm{H}$, Brinck $\mathrm{T}$, Hermunen $\mathrm{H}$, et al. Laparoscopic surgery for chronic groin pain in athletes is more effective than nonoperative treatment: a randomized clinical trial with magnetic resonance imaging of 60 patients with sportsman's hernia (athletic pubalgia). Surgery 2011;150:99-107.
7. van Veen RN, de Baat P, Heijboer MP, et al. Successful endoscopic treatment of chronic groin pain in athletes. Surg Endosc 2007;21:189-93.

8. Simons MP, Aufenacker T, Bay-Nielsen M, et al. European Hernia Society guidelines on the treatment of inguinal hernia in adult patients. Hernia 2009;13:343-403.

9. Caudill P, Nyland J, Smith C, et al. Sports hernias: a systematic literature review. BrJ Sports Med 2008;42:954-64.

10. Jansen JA, Mens JM, Backx FJ, et al. Treatment of longstanding groin pain in athletes: a systematic review. Scand J Med Sci Sports 2008;18:263-74.

11. Farrar JT, Young JP, LaMoreaux L, et al. Clinical importance of changes in chronic pain intensity measured on an 11-point numerical pain rating scale. Pain 2001;94:149-58. http://www.ncbi. nlm.nih.gov/pubmed/11690728 (accessed 6 Oct 2014).

12. Thorborg K, Branci S, Stensbirk F, et al. Copenhagen hip and groin outcome score (HAGOS) in male soccer: reference values for hip and groin injury-free players. Br J Sports Med 2014;48: 557-9.

13. Wilson JJ, Furukawa M. Evaluation of the patient with hip pain. Am Fam Physician 2014;89:27-34.

14. Marks MC, Alexander J, Sutherland $\mathrm{DH}$, et al. Clinical utility of the Duncan-Ely test for rectus femoris dysfunction during the swing phase of gait. Dev Med Child Neurol 2003;45: 763-8.

15. Harvey D. Assessment of the flexibility of elite athletes using the modified Thomas test. Br J Sports Med 1998;32:68-70.

16. Burgmans JP, Voorbrood CE, Schouten N, et al. Three-month results of the effect of Ultrapro or Prolene mesh on post-operative pain and well-being following endoscopic totally extraperitoneal hernia repair (TULP trial). Surg Endosc 2015;29:3171-8.

17. Langeveld HR, van't Riet M, Weidema WF, et al. Total extraperitoneal inguinal hernia repair compared with Lichtenstein (the LEVEL-Trial): a randomized controlled trial. Ann Surg 2010;251:819-24. 